\title{
EMBRYONAL RHABDOMYOSARCOMA: CASE REPORT
}

\author{
Sadashiva Gowda $\mathrm{H}^{1}$
}

\section{HOW TO CITE THIS ARTICLE:}

Sadashiva Gowda H. "Embryonal Rhabdomyosarcoma: Case Report". Journal of Evolution of Medical and Dental Sciences 2015; Vol. 4, Issue 70, August 31; Page: 12270-12273, DOI: 10.14260/jemds/2015/1771

\begin{abstract}
Rhabdomyosarcoma is a malignant tumor of striated muscle origin.[1] Rhabdomyosarcoma of the head and neck is primarily a disease of the first decade of life and it is the most common soft tissue sarcoma in children. ${ }^{[2]}$
\end{abstract}

KEYWORDS: Rhabdomyosarcoma, Soft tissue sarcoma.

CASE REPORT: An 11yrs. old girl presented with swelling over right side of nose, Cheek and lip since 2 months. On examination a polypoid mass involving the right side of nose, Cheek and lip. Laboratory investigations were within normal limits. Diagnosis was confirmed by Histopathological examination.

DISCUSSION: Rhabdomyosarcoma is the most common malignant soft tissue tumor in childhood. The majority of these tumors are found in the head and neck, genitourinary tract and the extremeties.[2,3] However, they can occur anywhere in the body. Other less common primary sites include the trunk, chest wall and abdomen. They arise from the primitive mesenchymal cells that are capable of differentiating into skeletal muscle.[1] Childhood Rhabdomyosarcoma, a soft tissue tumor accounts for approximately $35 \%$ of the cases among children 0 to $14 \mathrm{yrs}$. and $2 \%$ of the cases among adolescent and young adults 15-19 yrs. of age.[2,3]

Most cases of Rhabdomyosarcoma occur sporadically with no recognized predisposing factor or risk factor, though a small proportion are associated with genetic conditions. These conditions include Li-Fraumeni Syndrome, Neurofibromatosis and Beckwieth-Weidemann syndrome.[4] Rhabdomyosarcoma vary in histology and have been divided into four subtypes. Embryonal, botryoid, alveolar and pleomorphic. The embryonal subtype contains more than half of all cases.[5,6] Rhabdomyosarcoma usually present as slowly or rapidly enlarging masses when located over surface of the body.[2]

Survival depends on the extent of the disease at the time of diagnosis. Diagnostic radiology has an important role to play in the demonstration of this. The primary tumor has no pathognomonic appearances. The main role of a diagnostic radiology is detection of metastasis. [3] Plain films helps to differentiate between purely soft tissue tumors and tumors arising from bone. The presence of calcification can point to a specific diagnosis. ${ }^{[4]}$ On CT, rhabdomyosarcoma are poorly defined, in homogenous tumors that enhances to the same degree as skeletal muscle. Bone destruction may be present.

Because of its greater soft tissue contrast MRI is the preferred method for evaluation of soft tissue tumor. On T1-Weighted images, signal intensity is similar to that of skeletal muscle. On T2Weighted, proton density, STIR sequences the signal intensity is hyper intense relative to skeletal muscle. The tumor enhances avidly post gadolinium administration. ${ }^{[3]}$

Treatment of rhabdomyosarcoma is a multimodality effort, initial efforts are aimed at surgical resection of the tumor, always followed by chemotheraphy and radiotheraphy.[5] 


\section{CASE REPORT}

Fig. 1: Axial Cect Showing Well Enhancing Mass Involving the Right Side of Nose.

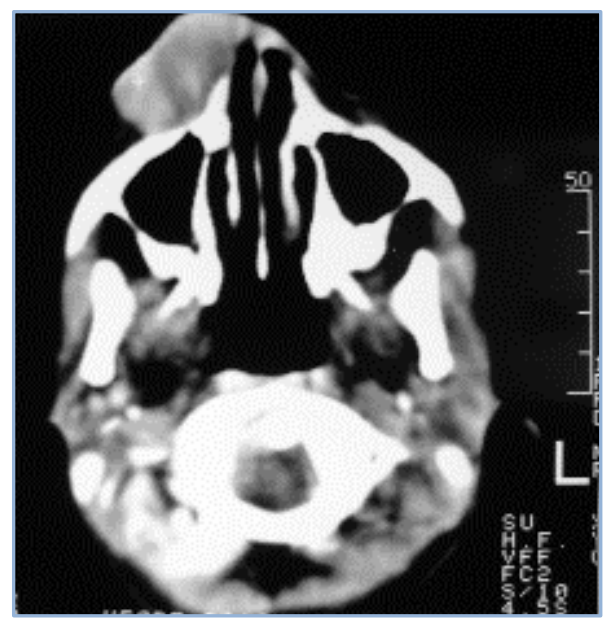

\section{Fig. 1}

Fig. 2: Axial Cect Showing Well Enhancing Mass Involving the Right Side of Nose, Cheek and Lip.

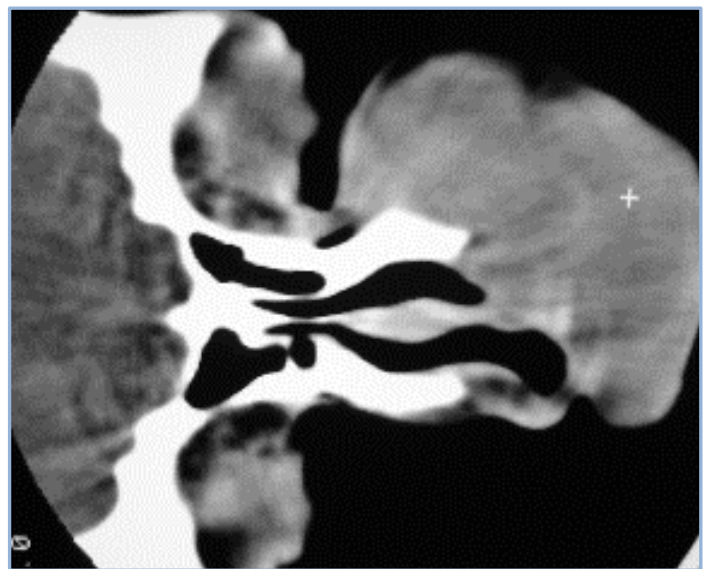

Fig. 2

Fig. 3: LP View of Embryonal Rhabdomyosarcoma with alternating cellular and myxoid areas show round to oval or spindle shaped cells.

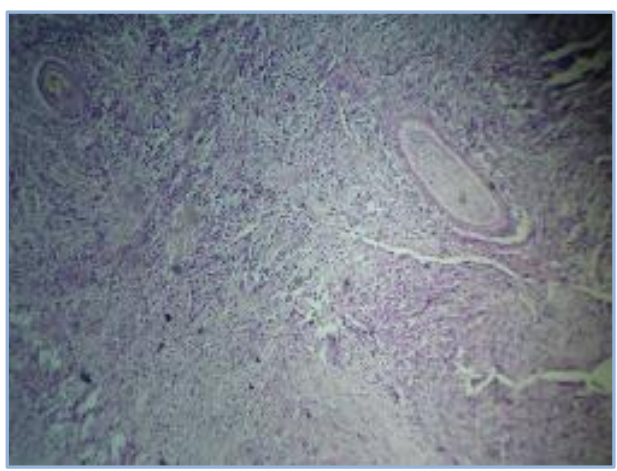

\section{Fig. 3}




\section{CASE REPORT}

Fig. 4: LP View of Embryonal Rhabdomyosarcoma showing scattered cells with eosinophilic cytoplasm and prominent nucleoli having eosinophilic fibrillar cytoplasm arranged around the nucleus.

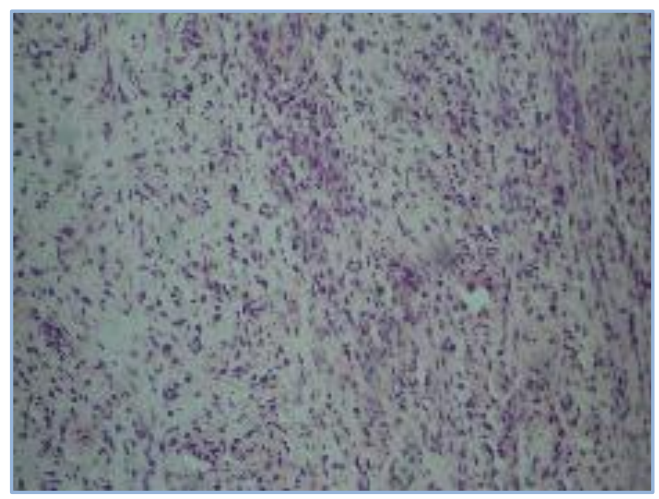

Fig. 4

Fig. 5: HP View of Embryonal Rhabdomyosarcoma showing elongated rhabdomyoblasts with distinct cross striations and vesiculated nuclei and abnormal mitoses.

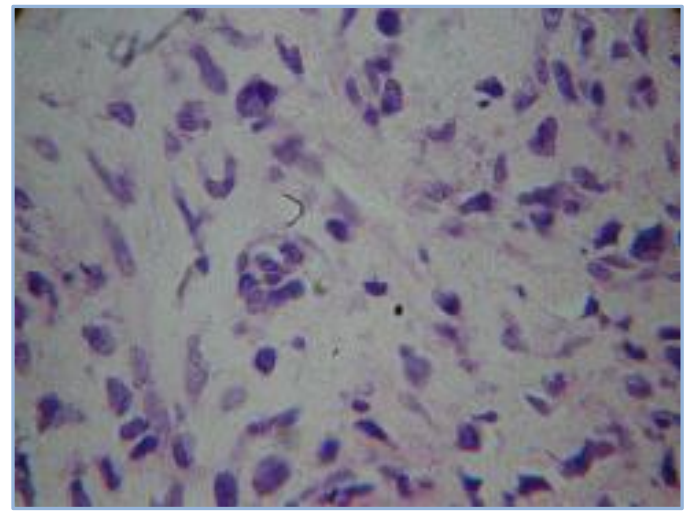

Fig. 5

\section{REFERENCES:}

1. Cole RR, Cotton RT, Pediatric malignancies In: Bailey BJ, Edn Head and neck surgery, Otolaryngology, Philadelphia: Lippincott Williams and Wilkins; 1993: 1388-96.

2. Bradley N. Delman. Skin and soft tissue lesions. In: Head and Neck imaging. $4^{\text {th }}$ Edn, Philadelphia; Mosby 2003: 2197-99.

3. Dillon E Parkin GJ. The role of diagnostic radiology in the diagnosis and management of rhabdomyosarcoma in young persons. Clinical Radiology 29(1): 53- 9, 1978 Jan.

4. Kelly KM, Wormer RB, Sorenson PH: Common and variant gene fusions predict distinct clinical phenotype in rhabdomyosarcoma: J Clin Oncol 1997, May 15(5): 1831-6.

5. Meyer WH, Spant SL: Soft tissue sarcomas of childhood: Cancer Treat Rev 2004 May: 30(3).

6. Mills SE. The Nose, paranasal sinuses and nasopharynx. In: Sternberg's diagnostic surgical pathology. $4^{\text {th }}$ ed, Philadelphia: Lippincott W\&W; 2004: 963-1006. 


\section{AUTHORS:}

1. Sadashiva Gowda H.

\section{PARTICULARS OF CONTRIBUTORS:}

1. Associate Professor, Department of Radio diagnosis, Vijayanagar Institute of Medical Sciences, Bellary.

FINANCIAL OR OTHER COMPETING INTERESTS: None

\section{NAME ADDRESS EMAIL ID OF THE}

CORRESPONDING AUTHOR:

Dr. Sadashiva Gowda H, Department of Radio Diagnosis, Vijayanagar Institute of Medical Sciences, Bellary, Karnataka.

E-mail: drsadashiv27@yahoo.com

Date of Submission: 02/08/2015.

Date of Peer Review: 04/08/2015.

Date of Acceptance: 25/08/2015.

Date of Publishing: 31/08/2015. 